\title{
TRATAMIENTO DE LODOS RESIDUALES DE UNA INDUSTRIA CERVECERA A TRAVÉS DE FERMENTACIÓN HOMOLÁCTICA PARA LA PRODUCCIÓN ACELERADA DE ABONO ORGÁNICO
}

\section{TREATMENT OF SEWAGE SLUDGE FROM A BREWING INDUSTRY THROUGH HOMLACTIC FERMENTATION FOR THE ACCELERATED PRODUCTION OF AN ORGANIC FERTILIZER}

\author{
Beatriz Esther Cupe Flores ${ }^{1}$ y Juan Gabriel Juscamaita Morales ${ }^{2}$
}

\begin{abstract}
Resumen
Los lodos residuales de una Planta de Tratamiento de Aguas Residuales (PTAR) de la industria cervecera se generan en grandes volúmenes causando problemas de contaminación, sin embargo, estos pueden ser un sustrato favorable para elaborar abonos orgánicos. La presente investigación tiene como objetivo elaborar Abono Líquido Acelerado (ALA), usando dichos lodos residuales, a través de fermentación homoláctica, empleando para ello el consorcio microbiano B-lac y melaza. Veinticuatro combinaciones diferentes y un control fueron tratados por 5 días a $40{ }^{\circ} \mathrm{C}$, bajo un Diseño Completo al Azar con arreglo factorial 5x5. Asimismo, se utilizó la prueba de agrupación de Tukey $(\mathrm{p}<0.05)$ para determinar diferencias significativas entre tratamientos y la de Mínimos Cuadrados para las medias. El mejor tratamiento fue el T9 con $20 \%$ melaza y $5 \%$ B-lac, presentando el menor pH (3.13) y el mayor porcentaje de ácido láctico (3.71\%), manteniendo su estabilidad por 30 días. La evaluación microbiológica del T9 estuvo libre de coliformes totales, coliformes fecales y parásitos; además, según el análisis agronómico, se obtuvieron para el abono líquido acelerado (ALA): $12.94 \%$ de materia orgánica, $1825.6 \mathrm{ppm}, 600 \mathrm{ppm}$ y $5800 \mathrm{ppm}$ de N, P y K respectivamente. Los metales pesados $\mathrm{Pb}, \mathrm{Cd}$ y $\mathrm{Cr}$ estuvieron dentro de los límites permisibles, según normativa internacional. En la prueba de bioensayo de toxicidad en semillas de lechuga (Lactuca sativa) se determinó que la dosis $0.1 \%$ del ALA no fue perjudicial para la germinación y crecimiento normal de las plántulas, verificándose por un Índice de Germinación (IG) mayor de 80\% (94.9\%). En conclusión, el abono orgánico de lodo residual de industria cervecera mostró una buena calidad agronómica.
\end{abstract}

Palabras clave: lodo residual, abono orgánico, fermentación homoláctica, bacterias acidolácticas.

\begin{abstract}
The residual sludge from a Waste Water Treatment Plant (WWTP) of the brewing industry are produced in large volumes, causing pollution problems. However, this can constitute a favorable substrate to make organic fertilizers in order to improve the quality of eroded soils. The present research aims to develop an Accelerated Liquid Fertilizer (ALF) taking advantage of the afore mentioned residual sludges through the homolactic fermentation process and using other inputs, such as a microbial consortium (B-lac) and cane molasses. Twenty-four different combinations of experimental units (T1-T24) and one control (T0) were treated for 5 days at $40{ }^{\circ} \mathrm{C}$, under a Full Random Design with $5 \times 5$ Factorial Arrangement. Also, the Tukey group test $(\mathrm{p}<0.05)$ was used to determine significant differences between treatments and the least squares for the means. The best treatment was T9 with 20\% molasses and 5\% B-lac, presenting the lowest pH (3.13) and the highest percentage of lactic acid $(3.71 \%)$, maintaining its stability for 30 days. The microbiological evaluation of T9 resulted in it being free of total coliforms, fecal coliforms and parasite eggs. In addition, according to the agronomic analysis, ALF presented $12.94 \%$ of organic matter, 1825.6 ppm, $600 \mathrm{ppm}$ and $5800 \mathrm{ppm}$ of $\mathrm{N}, \mathrm{P}$ and $\mathrm{K}$ respectively. The heavy metals $\mathrm{Pb}, \mathrm{Cd}$ and $\mathrm{Cr}$ were within the permissible limits according to international regulations. In the lettuce (Lactuca sativa) seed toxicity bioassay, it was determined that a $0.1 \%$ dose of ALF was not detrimental to germination and normal growth of the seedlings; verified by a germination rate greater than $80 \%$. In conclusion, the organic fertilizer of residual sludge from a brewing industry showed good agronomic quality.
\end{abstract}

Key words: residual sludge, organic fertilizer, homolactic fermentation, acidolactic bacteria. 


\section{Introducción.}

El tratamiento de aguas residuales, tanto municipales como industriales, tiene como objetivo remover los contaminantes presentes, con el fin de hacerlas aptas para otros usos o bien para evitar daños al ambiente. Sin embargo, el tratamiento del agua trae siempre como consecuencia la formación de subproductos llamados lodos residuales. Estos se originan como producto de la concentración de sólidos contenidos en el efluente (lodos primarios), o de la formación de nuevos sólidos suspendidos (lodos activados) resultantes de los sólidos disueltos de las aguas residuales municipales e industriales (Morales, 2005). Asimismo, los lodos son material de desecho que contienen compuestos orgánicos sólidos, semisólidos o líquidos producidos durante el proceso de tratamiento mecánico, biológico y/o químico de purificación de las aguas servidas (Marambio \& Ortega, 2003); además, contienen gran cantidad de materia orgánica, microorganismos patógenos, macro y micro nutrientes, metales pesados y agua (Cuevas et al., 2006). La disposición final de los lodos residuales provenientes de una Planta de Tratamiento de Aguas Residuales (PTAR), corresponden a operaciones costosas de una planta de tratamiento, debido al alto costo de la instalación de reactores estabilizadores de lodos y sistemas de deshidratación e incineración, además del transporte a los sitios de disposición final (Morales, 2005). Por tal motivo la mayor parte de los lodos generados en los procesos son vertidos en los sistemas de alcantarillado, en cuerpos de aguas superficiales y, en el mejor de los casos, dispuestos en rellenos sanitarios o incinerados, sin que se tomen las medidas de protección adecuadas para evitar la contaminación del suelo, de los cuerpos receptores y del acuífero, provocando un problema ambiental y de salud pública mayor del que se pretende resolver (Oropeza, 2006). Dentro de las agroindustrias, la industria cervecera genera efluentes con alta carga de materia orgánica, sólidos y otras sustancias (Yabroudi et al., 2009). Además, produce, entre otros, un residuo que proviene del tratamiento aeróbico en sus plantas de depuración. Al final del tratamiento aeróbico resulta la formación de un material pastoso, con alto contenido en humedad, de coloración pardusca a negra, de aspecto desagradable $\mathrm{y}$, dependiendo de la eficiencia del proceso, con fuerte mal olor, que recibe el nombre de lodo biológico (Braile \& Cavalcanti, 1993). La mezcla y tratamiento conjunto de todos los materiales residuales provoca la presencia de microorganismos patógenos (virus, bacterias, hongos, protozoos y helmintos) en el lodo (Blum \& Feachem, 1985; PereiraNeto et al., 1987). Por otro lado, estos lodos están constituidos básicamente de materia orgánica y es una gran incoherencia el hecho de que las industrias gasten elevadas sumas de capital para enterrarlos o incinerarlos con el fin de eliminar un componente que es escaso en general en todos los suelos tropicales
(Aloisi, 1995). La presente investigación tiene como objetivo elaborar Abono Líquido Acelerado (ALA) a partir de lodos residuales generados en la planta de tratamiento de aguas residuales de una industria cervecera, a través de un proceso de fermentación homoláctica, empleando para ello el consorcio microbiano Bio-lac (B-lac: consorcio de bacterias probióticas) y melaza como fuente de nutrientes. De esta manera también determinar la combinación de melaza y B-lac que genera un producto de mayor estabilidad ( $\mathrm{pH}$ bajo), con buen contenido de nutrientes y/o con reducción considerable de patógenos.

\section{Materiales y métodos.}

La etapa experimental de este estudio se llevó a cabo en el Laboratorio de Biotecnología Ambiental y Biorremediación del Departamento de Biología de la Facultad de Ciencias en la Universidad Nacional Agraria la Molina - UNALM.

Insumos para elaboración de abono orgánico

El consorcio microbiano B-lac $\AA$, cultivo que contiene un consorcio de bacterias acidolácticas (BAL), fue elaborado en el laboratorio de Biotecnología Ambiental y Biorremediación de la Facultad de Ciencias de la UNALM. La melaza de caña se obtuvo del establo de la UNALM. El lodo biológico residual de industria cervecera fue provisto por la planta de tratamiento de aguas residuales de la empresa AMBEV Perú S.A.C. ubicada en San Juan de Lurigancho - Lima.

Tratamiento del lodo residual

Los lodos residuales fueron ensayados con insumos de estudio denominados factor melaza y factor B-lac (inóculo de bacterias acidolácticas), en las proporciones de $5 \%, 10 \%, 15 \%$ y $20 \%$ para cada factor en combinación con los lodos residuales, como se muestra en la Tabla 1. Se obtuvieron un control y 24 tratamientos, con tres repeticiones cada uno, los cuales contenían $500 \mathrm{~g}$ de mezcla por cada unidad experimental. Se observa también la codificación usada a lo largo del trabajo de investigación.

El lodo residual tratado se dispuso en envases cerrados herméticamente para evitar contaminaciones y crear un ambiente anaeróbico cubriendo la superficie del preparado con una lámina de un plástico fino. Cada tratamiento fue incubado a $40{ }^{\circ} \mathrm{C}$ por 5 días.

Métodos de Análisis

Medición del pH

Se realizó diariamente durante los 5 días de

Tabla 1. Combinaciones de Lodo, Nutrientes y B-lac.

\begin{tabular}{|c|c|c|c|c|c|c|}
\hline \multirow{2}{*}{\multicolumn{2}{|c|}{$\begin{array}{l}\text { BAL } \\
\text { Nutrientes }\end{array}$}} & \multicolumn{5}{|c|}{ B-LAC (\%) } \\
\hline & & 0 & 5 & 10 & 15 & 20 \\
\hline \multirow{5}{*}{ 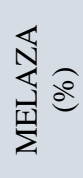 } & 0 & T0 & T5 & $\mathrm{T} 10$ & $\mathrm{~T} 15$ & $\mathrm{~T} 20$ \\
\hline & 5 & $\mathrm{~T} 1$ & T6 & $\mathrm{T} 11$ & $\mathrm{~T} 16$ & $\mathrm{~T} 21$ \\
\hline & 10 & $\mathrm{~T} 2$ & $\mathrm{~T} 7$ & $\mathrm{~T} 12$ & $\mathrm{~T} 17$ & $\mathrm{~T} 22$ \\
\hline & 15 & T3 & $\mathrm{T} 8$ & $\mathrm{~T} 13$ & T18 & $\mathrm{T} 23$ \\
\hline & 20 & $\mathrm{~T} 4$ & T9 & $\mathrm{T} 14$ & T19 & $\mathrm{T} 24$ \\
\hline
\end{tabular}


incubación a través del método del potenciómetro y la medición directa introduciendo el electrodo en la muestra, tomando en cuenta el día 0 inicial. El equipo se calibró previamente utilizando las soluciones buffer pH 4 y pH 7.

Medición del porcentaje de acidez titulable

Se realizó diariamente durante los 5 días de incubación, tomando en cuenta el día 0 inicial, mediante la medición indirecta del ácido láctico titulable, empleando la metodología de la AOAC (1998). Dicho método consiste en la titulación del ácido presente en la muestra con el Hidróxido de Sodio $(\mathrm{NaOH}) 0.1 \mathrm{~N}$ teniendo como punto final al cambio de $\mathrm{pH}$ del indicador fenolftaleína a un viraje de $\mathrm{pH} 8.1 \pm$ 0.2. Se pesó 10 gramos de la muestra y se diluyó en 50 $\mathrm{ml}$ de agua destilada, para luego tomar una alícuota de $10 \mathrm{ml}$, añadiéndole unas 3-4 gotas de fenolftaleína y se tituló con $\mathrm{NaOH} 0.1 \mathrm{~N}$. El porcentaje de ácido láctico titulable en las muestras se calculó con la siguiente fórmula (1):

(1) \% Ácidolácticotitulable $=\frac{\mathrm{G} * \mathrm{~N} * \mathrm{f} * 100}{m}$

Donde:

$\mathrm{G}=$ gasto de $\mathrm{NaOH}(\mathrm{ml})$

$\mathrm{N}=$ normalidad del $\mathrm{NaOH}$

$\mathrm{m}=$ masa de la muestra $(\mathrm{g})$

$\mathrm{f}=$ factor de conversión $(0.090)$

Se realizaron 3 repeticiones de este procedimiento. Parámetros físico-químicos

La caracterización del lodo residual, ALA y biosol de lodo residual para su análisis agronómico, se realizó en el Laboratorio de Suelos, Plantas, Aguas y Fertilizantes (LASPAF) en la UNALM, donde se llevaron a cabo los análisis de $\mathrm{pH}$, conductividad eléctrica, sólidos totales, materia orgánica en solución, macro-nutrientes $(\mathrm{C}, \mathrm{N}, \mathrm{P}, \mathrm{K}, \mathrm{Ca}, \mathrm{Mg}, \mathrm{Na}$ ), micronutrientes $(\mathrm{Fe}, \mathrm{Cu}, \mathrm{Zn}, \mathrm{Mn}, \mathrm{B})$ y metales pesados $(\mathrm{Cd}$, $\mathrm{Pb}, \mathrm{Cr}$ ) siguiendo la metodología de Capman \& Pratt, (1973). Para la determinación del contenido de C, N, P y $\mathrm{B}$ se emplearon los métodos estandarizados de Walkley y Black, Kjeldahl, Amarillo de Vanadato y Curmina, respectivamente; mientras que la determinación del contenido de $\mathrm{K}, \mathrm{Ca}, \mathrm{Mg}, \mathrm{Na}, \mathrm{Fe}, \mathrm{Cu}$, $\mathrm{Zn}, \mathrm{Mn}, \mathrm{Cr}, \mathrm{Pb}$ y Cd se realizó mediante espectrometría de absorción atómica.

Parámetros Microbiológicos y Parasitológicos

Para el lodo residual, ALA y biosol de lodo residual, se determinó la población de coliformes totales y coliformes fecales en el Laboratorio de Ecología Microbiana y Biotecnología "Marino Tabusso" de la UNALM con el método del Número más Probable (NMP) establecido por la International Commission on Microbiological for Food (ICMSF, 1983). Asimismo, se realizó un análisis parasitológico para el conteo microscópico de huevos de helmintos, según la metodología de la World Health Organization (WHO,
2004) en el Laboratorio de Parasitología de la Facultad de Veterinaria y Zootecnia en la Universidad Peruana Cayetano Heredia.

Selección del mejor tratamiento

Para la elección del mejor de los 24 tratamientos, se tomó en cuenta los siguientes criterios seguidos por Peña (2008): el pH debe ser menor a 4.5, no debe presentar mal olor ni olores fuertes y que no tengan formación de capas de microorganismos, sean mohos o levaduras. Asimismo, se tuvo como criterio el grado de significación de la prueba estadística en cuanto al efecto de interacción de los factores Melaza y B-lac sobre el parámetro $\mathrm{pH}$ y ácido láctico. Luego de seleccionado el mejor tratamiento, se procedió a hacer la separación de la parte líquida (ALA) y parte sólida (biosol) del abono orgánico con una prensa hidráulica. Estabilidad del abono líquido de lodo residual

La estabilidad del producto obtenido, ALA de lodo residual, se realizó en 30 días, mediante evaluaciones de $\mathrm{pH}$ y porcentaje de ácido láctico a los días 5, 10, 15, 20,25 y 30 , tomados después de finalizado el $5^{\text {to }}$ día de fermentación de las muestras según los tratamientos.

Ensayo de toxicidad aguda con semillas de lechuga (Lactuca sativa)

Se utilizaron semillas de lechuga (Lactuca sativa L.), variedad Hardy sin fungicidas, obtenidas del Centro de Investigación de Hidroponía y Nutrición Mineral de la UNALM. Se realizaron los tratamientos con las diluciones reportadas por Peralta (2010), por lo cual se utilizó la misma concentración de inhibición media utilizando como control agua de pozo del centro de Investigación de Hidroponía y Nutrición Mineral de la UNALM, la cual fue utilizada también para hacer las diluciones. Las condiciones usadas para evaluar el efecto del abono líquido de lodo residual en la germinación, crecimiento y desarrollo de las plántulas de lechuga en sus primeros estadios fueron las dispuestas por Sobrero \& Ronco (2004). Se usaron 480 semillas de lechuga de L. sativa, variedad Hardy, que fueron distribuidas en 24 placas petri o unidades experimentales con 20 semillas cada una y 3 repeticiones por tratamiento. Para evaluar el efecto en la elongación de la radícula, se midió dicha parte de la planta usándose papel milimetrado, teniendo en cuenta que la medida de la elongación de la radícula se considera desde el nudo (región más engrosada de transición entre la radícula y el hipocótilo) hasta el ápice radicular. Los resultados se reportaron mediante el IG (Índice de Germinación) según la metodología descrita por Tiquia (2000) (citado por Varnero et al., 2007), se calcula previamente el Porcentaje de Germinación Relativo (PGR) y el Crecimiento de Radícula Relativo (CRR) teniendo al tratamiento control como testigo, según las siguientes fórmulas (2, 3, 4):
(2) $P G R=\frac{\mathrm{N}^{\circ} \text { de semillas germinadas en el extracto }}{\mathrm{N}^{\circ} \text { de semillas germinadas en el testigo }}$ $* 100$ 
(3) $C R R=\frac{\text { Elongación de radículas en el extracto }}{\text { Elongación de radículas en el testigo }}$ $* 100$

(4) $I G=\frac{\mathrm{PGR} * \mathrm{CRR}}{100}$

\section{Análisis de datos}

El diseño estadístico empleado fue un Análisis de Variancia $(\mathrm{p}<0.05)$ para un Diseño Completo al Azar (DCA) en arreglo factorial de $5 \times 5$ con tres repeticiones. Para la determinación de diferencias significativas entre los tratamientos, se aplicó la prueba de agrupación de Tukey y la de Mínimos cuadrados para las medias. La comparación del porcentaje de germinación, fue realizada mediante un Análisis de Varianza $(p<0.05)$ para un DCA con tres repeticiones. Se empleó el programa Statistical Analysis Software (SAS) versión 8.2.

\section{Resultados y discusión.}

Caracterización del lodo residual de la PTAR de industria cervecera

Los resultados de los análisis microbiológicos de lodos residuales de PTAR se muestran en la Tabla 2. Se observa que la cantidad de coliformes totales y coliformes fecales fue baja y que no hubo presencia de parásitos. Esto pudo deberse a que estos lodos residuales provienen del tratamiento de aguas residuales de la producción de cerveza y no se mezclan con el agua residual del alcantarillado donde habría mayor probabilidad de encontrar parásitos y mayor cantidad de coliformes.

En la Tabla 3, se presentan los resultados del análisis físico-químico de interés agronómico (macronutrientes, micronutrientes y materia orgánica especial) del lodo residual. Los resultados permitieron evaluar el potencial de los lodos residuales como insumo para la elaboración de abono orgánico.

El valor de la conductividad eléctrica (C.E.) (6.94 dS. $\mathrm{m}^{-1}$ ) del lodo residual lo define como un material salino; respecto al $\mathrm{pH}$ (8.74) se le considera alcalino. Asimismo, presenta un buen contenido de materia orgánica $(51.51 \%)$, cuyo valor es superado solo por el lodo tratado con cal. Según Scora \& Chang (1997), estudios de la aplicación de lodos residuales en suelos agrícolas demuestran la posible utilización de lodos debido a la no transferencia de metales pesados a los

Tabla 2. Análisis microbiológico y parasitológico del lodo residual.

\begin{tabular}{lc}
\hline Parámetros & $\begin{array}{c}\text { Lodo } \\
\text { PTAR de cervecería }\end{array}$ \\
\hline $\begin{array}{l}\text { Enumeración de Coliformes } \\
\text { Totales }\left(\mathrm{NMP} / \mathrm{ml}^{-1} \text { ) }\right.\end{array}$ & $23 \times 10^{4}$ \\
$\begin{array}{l}\text { Enumeración de Coliformes } \\
\text { Fecales }\end{array}$ & $90 \times 10^{2}$ \\
$\left(\mathrm{NMP} / \mathrm{ml}^{-1}\right)$ & \\
Huevos de helmintos & Ausencia \\
\hline
\end{tabular}

productos de consumo humano. Adicionalmente, los lodos han sido utilizados en silvicultura para incrementar la productividad forestal, para reforestar y para estabilizar áreas deforestadas o perturbadas por la minería, la construcción, los incendios, el sobrepastoreo, erosión u otros factores (Brown et al., 2003). En la Tabla 4 se observa el contenido de metales pesados comparados con los límites permisibles establecidos por la Environmental Protection Agency (EPA).

Como se observa en la Tabla 4, los metales pesados de interés agronómico se encuentran muy por debajo de los límites permisibles establecidos por la EPA en biosólidos. Felipó (1995) afirma que la absorción de metales por las plantas está condicionada tanto por el elemento, su concentración y grado de disponibilidad, como por la especie vegetal y la interacción con macronutrientes. Este autor además dice que la biodisponibilidad de metales en el sistema suelo-planta por aporte de lodos se ha estimado a partir de los coeficientes de transferencia, observándose que el Cd y el $\mathrm{Zn}$ poseen los valores más elevados. Asimismo, parece que la biodisponibilidad es superior para $\mathrm{Cd}, \mathrm{Cu}$, $\mathrm{Ni}$ y $\mathrm{Zn}$ que, para $\mathrm{Pb}, \mathrm{Hg}$ y $\mathrm{Cr}$, pero incluso para los

Tabla 3. Análisis agronómico del lodo residual comparado con otros tipos de materiales orgánicos.

\begin{tabular}{|c|c|c|c|c|}
\hline $\begin{array}{c}\text { Parámetro } \\
\text { s }\end{array}$ & $\begin{array}{c}\text { Lodo } \\
\text { aerobio de } \\
\text { cervecería } \\
1\end{array}$ & $\begin{array}{l}\text { Estiércol } \\
\text { de } \\
\text { bovinos }^{2}\end{array}$ & $\begin{array}{c}\text { Lodo } \\
\text { aerobio } \\
\text { tratado } \\
\text { con cal }^{2}\end{array}$ & $\begin{array}{c}\text { Estiércol } \\
\text { de ovinos }\end{array}$ \\
\hline $\mathrm{pH}$ & 8.74 & - & - & \\
\hline $\begin{array}{l}\text { C.E. } \\
\left(\text { dS.m }{ }^{-1}\right)\end{array}$ & 6.94 & - & - & \\
\hline $\begin{array}{l}\text { Humedad } \\
(\%)\end{array}$ & 95.92 & 83.5 & 85 & 65 \\
\hline $\begin{array}{l}\text { Sólidos } \\
\text { totales }(\%)\end{array}$ & - & - & - & \\
\hline $\begin{array}{l}\text { Materia } \\
\text { Orgánica - } \\
\text { M.O (\%) } \\
\text { Macronutrie }\end{array}$ & tes (ppm) & 14.6 & 69.4 & 31.4 \\
\hline $\mathrm{N}$ & 32400 & $\begin{array}{l}20000- \\
80000\end{array}$ & 25000 & $\begin{array}{l}30000- \\
50000\end{array}$ \\
\hline $\mathrm{P}_{2} \mathrm{O}_{5}$ & 62800 & $\begin{array}{l}2000- \\
10000\end{array}$ & 9000 & $\begin{array}{l}4000- \\
8000\end{array}$ \\
\hline $\mathrm{K}_{2} \mathrm{O}$ & 5600 & $\begin{array}{l}10000- \\
30000\end{array}$ & 2000 & 1500 \\
\hline $\mathrm{CaO}$ & 46300 & - & - & $\begin{array}{l}20000- \\
30000\end{array}$ \\
\hline $\mathrm{MgO}$ & 7200 & $\begin{array}{l}10000- \\
15000\end{array}$ & - & 2000 \\
\hline $\mathrm{Na}$ & 27100 & $\begin{array}{l}10000- \\
30000\end{array}$ & - & 5000 \\
\hline \multicolumn{5}{|c|}{ Micronutrientes (ppm) } \\
\hline $\mathrm{Fe}$ & 6113 & - & - & - \\
\hline $\mathrm{Cu}$ & 265 & - & - & - \\
\hline $\mathrm{Zn}$ & 804 & - & - & - \\
\hline $\mathrm{Mn}$ & 341 & - & - & - \\
\hline B & 68 & - & - & - \\
\hline
\end{tabular}


Tabla 4. Resultado del análisis de metales pesados del lodo residual comparado con las normas de la EPA.

\begin{tabular}{ccc}
\hline $\begin{array}{c}\text { Metales } \\
\text { pesados } \\
(\mathrm{ppm})\end{array}$ & $\begin{array}{c}\text { Lodo residual de } \\
\text { PTAR de } \\
\text { cervecería }\end{array}$ & Norma EPA 503 \\
\hline $\mathrm{Pb}$ & 160.3 & 840 \\
$\mathrm{Cd}$ & 4.88 & 85 \\
$\mathrm{Cr}$ & 300.13 & 3000 \\
$\mathrm{Fe}$ & 6113 & - \\
$\mathrm{Cu}$ & 265 & 4300 \\
$\mathrm{Zn}$ & 804 & 7500 \\
$\mathrm{Mn}$ & 341 & - \\
\hline
\end{tabular}

elementos más móviles la cantidad de metal transferida al cultivo es inferior a $0.05 \%$ de la cantidad aplicada anualmente por aporte de lodos.

Evaluación del parámetro de $\mathrm{pH}$ en los tratamientos

El tratamiento T0, fue designado como control respecto a los demás tratamientos. Para los 24 tratamientos (T1 al T24), el valor del pH al inicio de la fermentación se determinó en valores mayores de 4 a 6 unidades. Respecto a los tratamientos que contenían $0 \%$ melaza, T15 y T20 resultaron con valores de $\mathrm{pH}$ menores a 6 respecto a T5 y T10. De los tratamientos que contenían $0 \%$ B-lac, T4 resultó con un valor de $\mathrm{pH}$ menor a 6 respecto a T1, T2 y T3. El tratamiento T6, fue el único de todos los tratamientos con lodo, melaza y B-lac que resultó con un $\mathrm{pH}$ mayor a 6 . Los tratamientos T23 y T24 registraron un $\mathrm{pH}$ inicial menor a 5. En las Figuras 1, 2, 3, 4 y 5, se muestra la variación del $\mathrm{pH}$ en los 5 días de evaluación.

Según criterios seguidos por Peña (2008), el pH del abono orgánico debe ser menor a 4.5 , ya que, de acuerdo a Garcés et al., (2004) en una fermentación láctica espontánea en condiciones anaerobias, las bacterias ácido lácticas fermentan los carbohidratos hidrosolubles, produciendo ácido láctico y en menor cantidad ácido acético, al generarse dichos ácidos el pH del material fermentado baja a un nivel que inhibe la presencia de microorganismos que inducen la

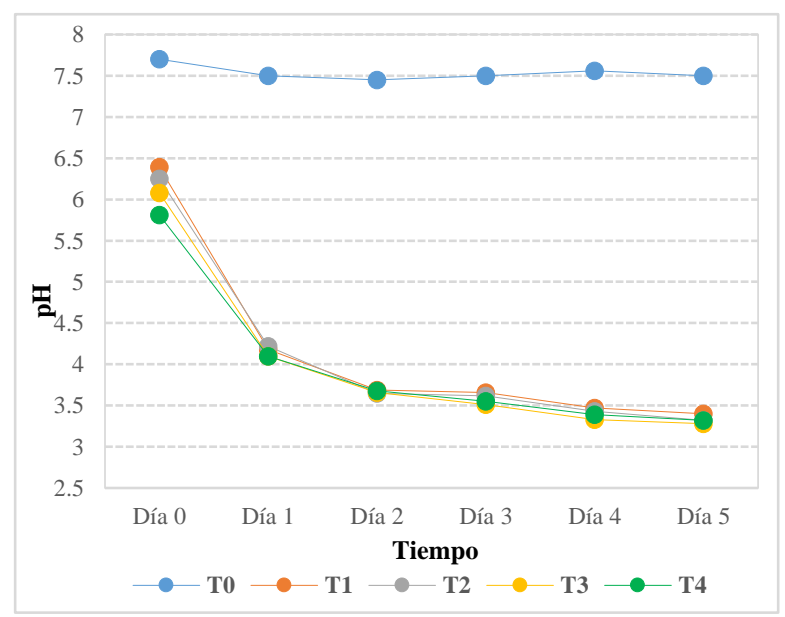

Figura 1. Variación promedio de pH del T0 al T4.

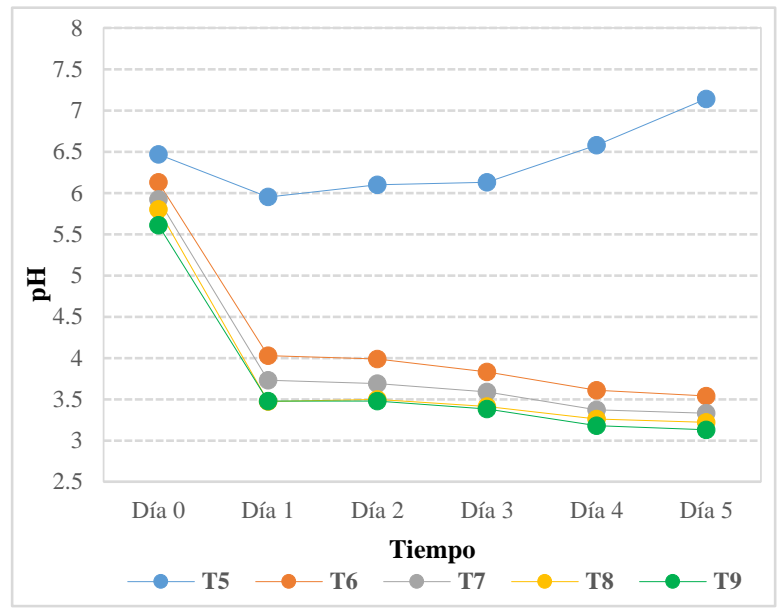

Figura 2. Variación promedio de pH del T5 al T9.

putrefacción. En este sentido, los tratamientos T0, T5, T10, T15 y T20, mostraron valores de $\mathrm{pH}$ mayores a 4.5 al quinto día de evaluación. Esta condición se dio debido a que dichos tratamientos no contenían fuente carbonada fácilmente fermentable (melaza), lo cual hizo que se produjeran condiciones para generar olores desagradables (putrefactos) que son el producto de una actividad microbiana no deseada donde predominan altas cantidades de coliformes (Tobía \& Vargas, 2000). Además, dichos tratamientos presentaron una capa blanquecina en la superficie con presencia de burbujas como resultado de los gases generados. Según García (2008) esto es debido a que las condiciones iniciales de pH mayores a 5, así como la temperatura de incubación de $40{ }^{\circ} \mathrm{C}$, favorecieron el desarrollo de la flora bacteriana que normalmente es inhibida por las bacterias lácticas (BAL) que producen ácido láctico. Los tratamientos T1, T2, T3 y T4 que no contenían fuente de bacterias acido lácticas (B-lac), resultaron, sin embargo, con valores de $\mathrm{pH}$ menores a 4.5 al quinto día de evaluación. Esto se debe posiblemente a que los lodos residuales, contenían inicialmente una población de bacterias lácticas, debido a que, los lodos biológicos

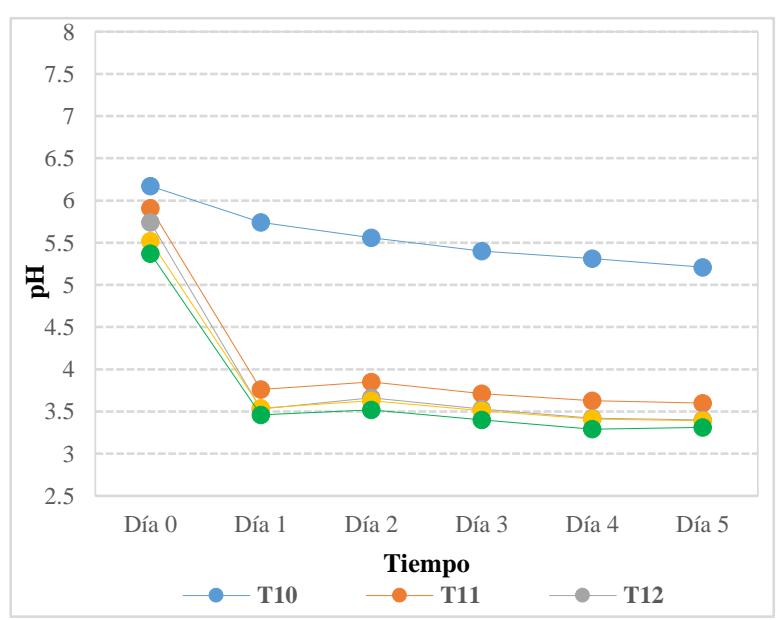

Figura 3. Variación promedio de pH del T10 al T14. 


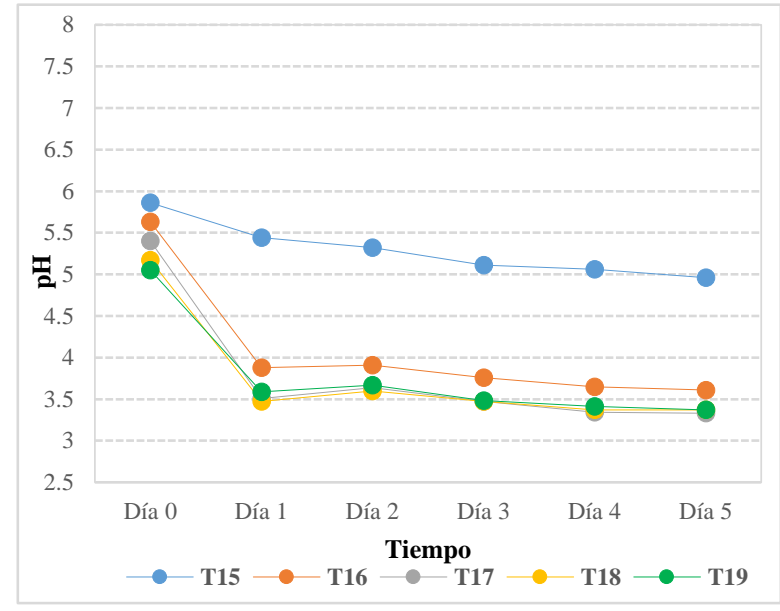

Figura 4. Variación promedio de pH del T15 al T19.

que provienen de un tanque de aireación con lodos activados contienen abundante biomasa y están representados generalmente por un $95 \%$ de bacterias y $5 \%$ de Protozoos y Metazoos (Di Marzio, 2004). Por tal razón, se sembró una alícuota de lodo residual en el medio agar MRS que permitió evidenciar un buen crecimiento de lactobacilos y otras bacterias ácido lácticas a $30{ }^{\circ} \mathrm{C}$, bajo condiciones anaeróbicas por 5 días. Se contaron $25 \times 10^{4} \mathrm{UFC}^{-1} \mathrm{~g}^{-1}$ en el lodo residual, estas bacterias ácido lácticas consumieron la fuente carbonada (melaza) y lograron disminuir el $\mathrm{pH}$. Respecto a los demás tratamientos (T6-T9, T11-T14, T16-T19 y T21-T24), se obtuvieron valores de $\mathrm{pH}$ menores a 4.5 y no presentaron características de olores desagradables ni la observación de una ligera o nula presencia de burbujas hasta el quinto día de evaluación, lo cual indica que las bacterias ácido lácticas presentes en el B-lac con las BAL presentes en el lodo comenzaron a producir ácido láctico disminuyendo los valores de $\mathrm{pH}$ hasta llegar a un valor mínimo de 3.13 en el T9; resultados similares fueron reportados por Guccione (2009), Román (2012) y Peralta (2010).

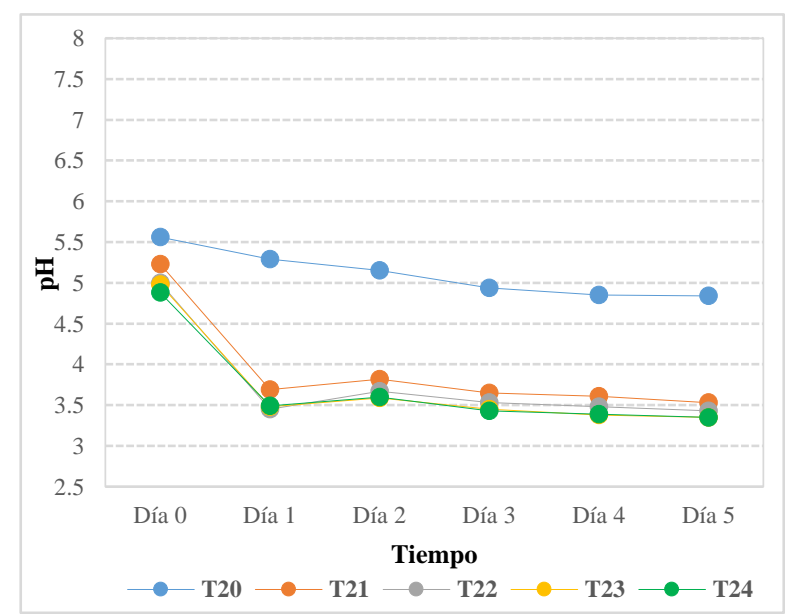

Figura 5. Variación promedio de pH del T20 al T24.
Evaluación del parámetro de ácido láctico en los tratamientos

Con respecto a la determinación inicial de acidez titulable expresado como ácido láctico titulable, los 24 tratamientos y el control presentaron un valor de porcentaje de ácido láctico menor al $1 \%$. Se procedió a la evaluación del ácido láctico desde el día 0 (día de inicio) hasta el día 5, según se muestra en las Figuras 6, 7, 8, 9 y 10. Con respecto a los tratamientos T0, T10, T15 y T20 (0\% melaza), los valores promedios del porcentaje de ácido láctico en estos tratamientos se mantuvieron menores del $1 \%$ hasta el 5 to día, debido a que no hubo azúcar fácilmente fermentable, no hubo producción de ácido láctico. Como se mencionó anteriormente estos tratamientos generaron burbujas y gases con olores desagradables. Según Madigan et al., (2004), la observación de producción de burbujas de anhídrido carbónico es indicador de microorganismo heterofermentadores.

Para los tratamientos T1, T2, T3 y T4 que no tenían la fuente de microorganismos (B-lac) el porcentaje de ácido láctico titulable promedio fue aumentando en los tratamientos en proporción a la cantidad de melaza añadida hasta llegar a un $2.84 \%$ en el T4. Esto debido a la población nativa de bacterias ácido lácticas presentes en el lodo residual que consumió la melaza para producir ácido láctico. En los demás tratamientos se observó que el ácido láctico fue aumentando en los cinco días debido a la actividad de bacterias ácido lácticas presentes tanto nativas como inoculadas (Blac) para llegar a valores de ácido láctico mayores de $1.5 \%$ hasta $3.71 \%$ en el T9. Rodríguez (2004) menciona que durante el proceso fermentativo las relaciones ecológicas que se implantan posibilitan que unos organismos surjan como dominantes numéricos y otros disminuyan en su número o desaparezcan. Asimismo, este proceso de ajuste ecológico en las fermentaciones mixtas puede ser consecuencia de la competencia por los nutrientes (Fuller, 1992; Henges, 1992; citados por Boucourt et al., 2006) y de la producción de sustancias antimicrobianas, como los ácidos orgánicos, bacteriocinas y peróxido de hidrogeno (Robredo y Torres, 2000; Rolfe, 2000; Brizuela, 2003 y Ogunbanwo et al. 2003; citados por Boucourt et al., 2006).

Análisis del parámetro pH y ácido láctico para la elección del mejor tratamiento

Como se observa en las Figuras 1 y 6 , el tratamiento T9 es aquel que muestra el pH más bajo (3.13) y el porcentaje de ácido láctico más alto (3.71\%) comparado con los demás tratamientos, y según lo mencionado en el análisis estadístico, existen diferencias significativas ( $p>0.05$ ) en cuanto al efecto de interacción de los factores Melaza y B-lac. De acuerdo a eso, se realizó la comparación de la mejor combinación de los factores Melaza y B-lac mediante la prueba de mínimos cuadrados para las medias y se observaron diferencias significativas $(p>0.05)$ entre las 


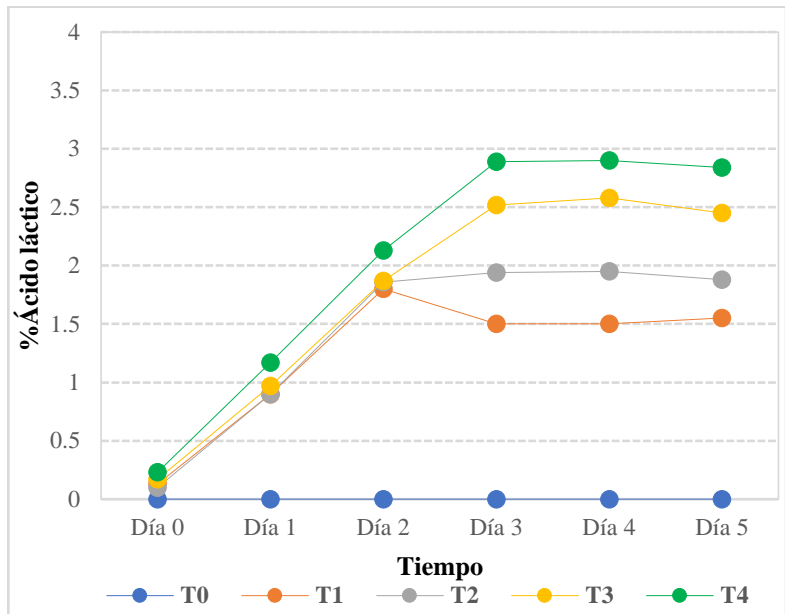

Figura 6. Variación de Ácido láctico del T0 al T4.

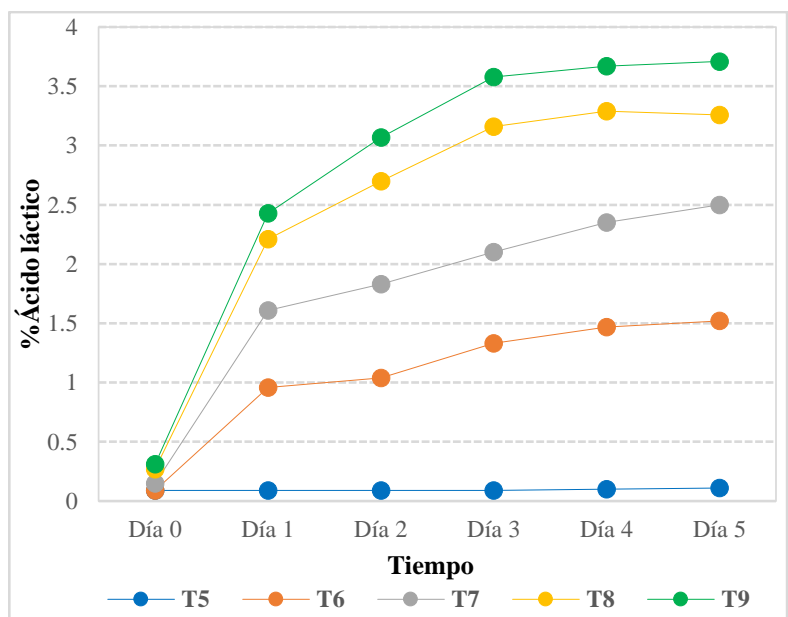

Figura 7. Variación de Ácido láctico del T5 al T9.

medias del porcentaje de ácido láctico con respecto al T9. Además, se realizó una prueba de Tukey ( $>>0.05$ ), en el cual se compararon las medias de los tratamientos con respecto al parámetro ácido láctico en el 5to día de evaluación para los factores Melaza y B-lac (Tabla 5).

Se observó que para el factor melaza, se obtuvo un mayor porcentaje de ácido láctico con un $20 \%$ de este, mientras que para el factor B-lac se obtuvo un mayor porcentaje de ácido láctico con un 5\%, $15 \%$ y $20 \%$ de este, entre estos tres porcentajes se escogió al 5\%. Estas proporciones de melaza $20 \%$ y B-lac $5 \%$, corresponden al tratamiento T9, por lo cual se escogió a este tratamiento como el mejor, además con estas proporciones se disminuyen costos e insumos, debido a que contiene menor porcentaje de B-lac (5\%), mayor cantidad de lodo (75\%) y mayor cantidad de Melaza (20\%).

Caracterización del abono orgánico de lodos residuales de industria cervecera

En la Tabla 6, se muestran los resultados del análisis microbiológico y parasitológico del abono orgánico producido después de su separación en ALA (Abono

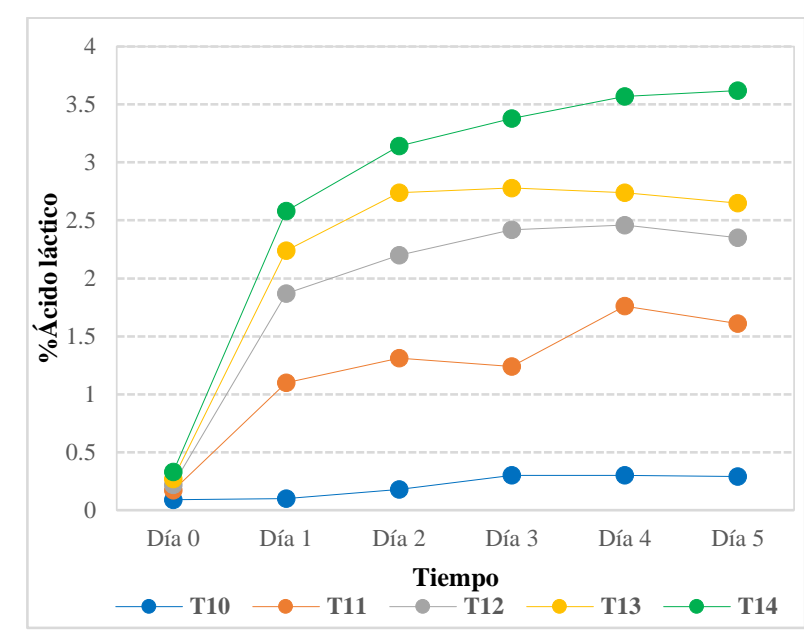

Figura 8. Variación de Ácido láctico del T10 al T14.

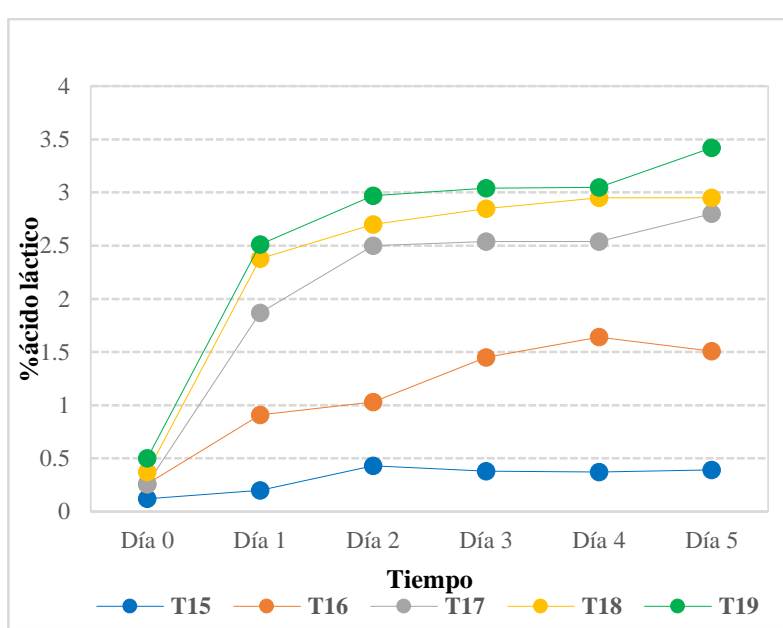

Figura 9. Variación de Ácido láctico del T15 al T19.

líquido acelerado) y biosol (abono orgánico sólido) para verificar la ausencia de microorganismos patógenos que puedan afectar su calidad e inocuidad.

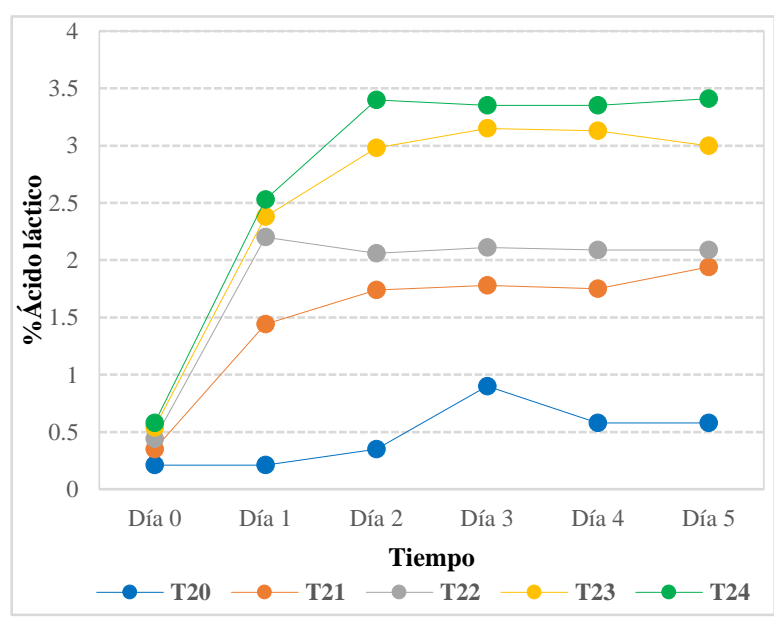

Figura 10. Variación de Ácido láctico del T20 al T24. 
Tabla 5. Resultados de la prueba de comparación HSD Tukey para el parámetro ácido láctico.

\begin{tabular}{ccc}
\hline Grupos & $\begin{array}{c}\text { Promedio } \\
\text { (\% ácido láctico) }\end{array}$ & $\begin{array}{c}\text { Porcentaje } \\
\text { de insumo } \\
(\%)\end{array}$ \\
\hline Melaza & 3.39 & 20 \\
A & 2.86 & 15 \\
B & 2.32 & 10 \\
C & 1.62 & 5 \\
D & 0.27 & 0 \\
E & & \\
B-lac & 2.22 & 5 \\
A & 2.21 & 15 \\
A & 2.20 & 20 \\
A & 2.11 & 10 \\
B & 1.74 & 0 \\
C & & \\
\hline
\end{tabular}

Los coliformes fecales son comúnmente utilizados como indicadores de contaminación fecal en aguas residuales. Su uso en lodos y biosólidos usualmente indica la eficiencia de los procesos de tratamiento en la destrucción de bacterias, y además regula la calidad de los biosólidos que pueden reusarse benéficamente (Castrejón et al., 2000). Con respecto estos microorganismos, después de los 5 días de tratamiento estuvieron ausentes tanto en el ALA como en el biosol. En total se disminuyeron 4 unidades de coliformes totales y 2 unidades de coliformes fecales de la carga microbiana inicial no deseada. El tiempo de disminución de carga microbiana del ALA de lodo residual fue menor (5 días) comparado con el abono preparado en forma artesanal reportado por Sotil (2007) cuya reducción de los niveles de coliformes totales y fecales al inicio de la biodegradación de los abonos de $10^{7}-10^{8} \mathrm{NMP} / 100 \mathrm{ml}$ llegó a ser 61 días con $10^{3}$ NMP/100 ml y cercano a cero a los 335 días. Se considera que la reducción en el pH es el principal efecto inhibidor de coliformes debido a la producción de ácidos orgánicos (Carrasco et al. 2002). Asimismo, la actividad antimicrobiana de las bacterias acidolácticas ha sido atribuida a la acumulación de los productos finales de los procesos de fermentación, como ácido láctico, dióxido de carbono, peróxido de hidrógeno, etc. o a la producción de bacteriocinas (Lindgren \& Dobrogoz, 1990). En la Tabla 7, se presentan los resultados del análisis fisicoquímico de interés agronómico (materia orgánica especial) del ALA de lodo residual.

Tabla 6. Análisis microbiológico y parasitológico del ALA y biosol de lodo residual.

\begin{tabular}{lcc}
\hline Parámetros & ALA & Biosol \\
\hline $\begin{array}{l}\text { Enumeración de Coliformes } \\
\text { Totales (NMP.ml }\end{array}$ & $<3$ & $<3$ \\
Enumeración de Coliformes & $<3$ & $<3$ \\
Fecales $\left(\mathrm{NMP} \mathrm{ml}^{-1}\right.$ ) & &
\end{tabular}

Fecales (NMP. ml-1)

Huevos de helmintos Ausencia Ausencia

Nota: Los valores de $<3$ indican ausencia de microorganismo
Tabla 7. Resultado del análisis agronómico del ALA de lodo residual y otros bioles.

\begin{tabular}{|c|c|c|c|c|c|}
\hline 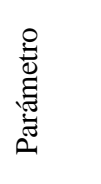 & $\begin{array}{c}\text { ALA } \\
\text { de } \\
\text { lodo } \\
\text { residua } \\
1\end{array}$ & $\mathrm{BC}^{1}$ & $\mathrm{BV}^{2}$ & $\begin{array}{c}\text { Fert } \\
\text { R.P.C }{ }^{3}\end{array}$ & $\begin{array}{c}\text { B. } \\
\text { Ulva } \\
\text { lactuc } \\
a^{4}\end{array}$ \\
\hline $\mathrm{pH}$ & 3.73 & 8.2 & 7.89 & 3.6 & 4.6 \\
\hline $\begin{array}{l}\text {..C.E. } \\
(\mathrm{dS} / \mathrm{m})\end{array}$ & 34.4 & 15.3 & 19.28 & 16.5 & 22.3 \\
\hline $\begin{array}{l}\text { M.O } \\
(\%)\end{array}$ & 12.94 & 5.4 & 5.28 & 148.42 & - \\
\hline \multicolumn{6}{|c|}{ Macronutrientes (ppm) } \\
\hline $\mathrm{N}$ & 1825.6 & 980 & 1876 & 9485 & 2214 \\
\hline $\mathrm{P}_{2} \mathrm{O}_{5}$ & 600 & 121 & 71.20 & 310 & 324 \\
\hline $\mathrm{K}_{2} \mathrm{O}$ & 5800 & 6760 & 1940 & 3296 & 7362 \\
\hline $\mathrm{CaO}$ & 1640 & 220.4 & 104.80 & 1672 & 873 \\
\hline $\mathrm{MgO}$ & 662 & 53.4 & 27.60 & 696 & 2835 \\
\hline $\mathrm{Na}$ & 690 & 542 & 3400 & 1072 & - \\
\hline \multicolumn{6}{|c|}{ Micronutrientes (ppm) } \\
\hline $\mathrm{Fe}$ & 109.8 & - & 0.16 & 30 & 994.5 \\
\hline $\mathrm{Cu}$ & 1.96 & - & 2.28 & 2.25 & 17.5 \\
\hline $\mathrm{Zn}$ & 8.7 & - & 1.36 & 4.20 & 30 \\
\hline $\mathrm{Mn}$ & 6.94 & - & 14.08 & 2.40 & 25.5 \\
\hline B & 4.13 & - & 5.20 & 21 & 62.32 \\
\hline
\end{tabular}

${ }^{1}$ Siura \& Dávila, 2008 (Biol de excretas de cuy); ${ }^{2}$ Biol Ventanilla Ciudad Saludable; ${ }^{3}$ Bossio Félix, 2007 (fertilizante orgánico basado en residuos de pescado y roca fosfatada); ${ }^{4}$ Aldón, 2008 (ensilaje de Ulva lactuca).

Como se observa en la Tabla 7, el ALA de lodo residual tiene un mayor contenido de materia orgánica, macro y micronutrientes con respecto a los bioles de Ventanilla y Casablanca. Pero con respecto a los demás bioles, en general presenta menos concentración de materia orgánica, macro y micro nutrientes, esto debido a la composición de cada sustrato utilizado para elaborar el abono. Además, el ALA de lodo residual posee una buena cantidad de hierro y supera en el contenido de fósforo y potasio al fertilizante de residuo de pescado y en fósforo y calcio al ensilado de Ulva lactuca. Por otro lado, el pH es ácido (menor a 4) y la conductividad eléctrica es elevada como en los bioles elaborados por Bossio (2007), Peralta (2010) y Román (2012). Guerreo (1993), citado por Peralta (2010), señala que en condiciones de $\mathrm{pH}$ alcalino, usual en estiércol y guano, el nitrógeno se pierde rápidamente, generando un fuerte olor amoniacal. Con respecto a la elevada conductividad eléctrica, es importante mencionar que dicho valor disminuye cuando se preparan las dosificaciones (dilución de 3-5 ml del biol por cada litro de agua de riego) según los requerimientos del cultivo al cual se aplica foliarmente (Peña, 2008; Aldón, 2008). Las características halladas en este compuesto, indican, según lo anotado por García (2008), que puede ser útil como enmienda para la rehabilitación de suelos sódicos, ya que presenta $\mathrm{pH}$ ácido y elevada concentración electrolítica (Suarez, 2009). Los biofertilizantes líquidos habitualmente se aplican directamente sobre los cultivos vía foliar, aunque también pueden ser aplicados al suelo, 
Tabla 8. Resultado del análisis agronómico del biosol de lodo residual y otros abonos orgánicos sólidos.

\begin{tabular}{|c|c|c|c|c|c|}
\hline 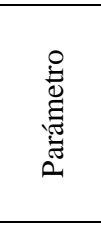 & $\begin{array}{c}\text { Biosol } \\
\text { de lodo } \\
\text { residua } \\
1\end{array}$ & $\begin{array}{c}\text { Comp } \\
\text { osta } \\
\text { de } \\
\text { Lodo } \\
\text { residu } \\
\text { al }^{1}\end{array}$ & $\begin{array}{c}\text { Guano } \\
\text { de } \\
\text { Invern } \\
a^{2}\end{array}$ & $\begin{array}{c}\text { Fast } \\
\text { Biosol } \\
3\end{array}$ & $\begin{array}{c}\text { Biosol } \\
\text { T13 }^{4}\end{array}$ \\
\hline $\mathrm{pH}$ & 3.94 & 6.5 & 8.27 & 4.48 & 4.73 \\
\hline $\begin{array}{c}\text { C.E } \\
(\mathrm{dS} / \mathrm{m})\end{array}$ & 16.7 & - & 10.92 & 10.64 & 21 \\
\hline $\begin{array}{l}\text { M.O } \\
(\%)\end{array}$ & 58.99 & 20.12 & 76.6 & 80.4 & 81.24 \\
\hline \multicolumn{6}{|c|}{ Macronutrientes (\%) } \\
\hline $\mathrm{N}$ & 2.62 & 0.93 & 2.13 & 1.43 & 2.12 \\
\hline $\mathrm{P}_{2} \mathrm{O}_{5}$ & 1.4 & 0.85 & 1.59 & 0.62 & 2.38 \\
\hline $\mathrm{K}_{2} \mathrm{O}$ & 2.32 & 0.014 & 3.03 & 3.03 & 4 \\
\hline $\mathrm{CaO}$ & 1.04 & 0.34 & 2.24 & 2.04 & 2.34 \\
\hline $\mathrm{MgO}$ & 0.46 & 0.06 & 1.17 & 0.5 & 0.87 \\
\hline $\mathrm{Na}$ & 0.28 & - & 0.53 & 0.18 & 0.27 \\
\hline \multicolumn{6}{|c|}{ Micronutrientes (ppm) } \\
\hline $\mathrm{Fe}$ & 1610 & 31.571 & - & - & 0.076 \\
\hline $\mathrm{Cu}$ & 124 & 158 & - & 45 & 26 \\
\hline $\mathrm{Zn}$ & 264 & 168 & - & 75 & 148 \\
\hline $\mathrm{Mn}$ & 73 & 244 & - & 70 & 152 \\
\hline B & 35 & - & - & 35 & 42 \\
\hline
\end{tabular}

${ }^{1}$ Beltrame et al., 1999 (Composta de lodo residual de cervecería); ${ }^{2}$ Kimura, 2005 (estiércol de vacuno y material vegetal); ${ }^{3}$ Peralta, 2010 (Biosol de origen vacuno); ${ }^{4}$ Román, 2012 (Biosol de excretas de cuy (Cavia porcellus)).

preferentemente cuando estén con coberturas (Suarez, 2009). Peña (2008) sugiere que este tipo de fertilizantes, al ser aplicados sobre el follaje, presentan la ventaja de resultar prácticos y eficientes, comparados con su aplicación vía radical, ya que dosis tan bajas dificultan su aplicación de manera uniforme. En la Tabla 8 , se presentan los resultados del análisis de interés agronómico (materia orgánica especial) del biosol de lodo residual.

En el caso del biosol de lodo residual, el contenido de nitrógeno es elevado ya que no se ha volatilizado en forma de amoniaco porque el $\mathrm{pH}$ de dicho biosol es ácido (3.94). Por otro lado, el contenido de fósforo es mayor que en la composta de lodo residual y el Fast biosol (biosol de origen vacuno), pero es superado por el Biosol T13 (Biosol de excretas de cuy, Cavia porcellus) y el guano de inverna (estiércol de vacuno y material vegetal). Respecto al contenido de $\mathrm{CaO}$ y $\mathrm{MgO}$, el biosol sólo supera a la composta de lodo residual. Analizando el contenido de micronutrientes, el biosol de lodo residual supera en la cantidad de Fe, $\mathrm{Cu}$ y Zinc a los 2 biosoles de origen animal. La concentración de Mn es superada por la composta de lodo residual y el biosol de excretas de cuy, además el Boro (B) se encuentra en cantidades similares con respecto a los demás biosoles. La cantidad de materia orgánica fue de $58.99 \%$, menor que los biosoles de origen animal y guano de inverna pero a su vez mayor que la composta de lodo residual. El tener una buena cantidad de materia orgánica es excelente para este tipo de abonos, ya que la materia orgánica es fuente de nutrientes para la microflora del suelo, así como, medio de soporte para los cultivos (Peralta (2010), citado por Román (2012)). En la Tabla 9 se observan los resultados de los metales pesados comparados con los límites permisibles establecidos por la EPA.

Estabilidad del ALA de lodo residual de PTAR de industria cervecera

La estabilidad del ALA de lodo residual, se estableció en base al control de $\mathrm{pH}$ y acidez titulable en porcentaje de ácido láctico además de observación de cambios físicos producidos por hinchamiento, olores y aspectos del producto del T9 por 30 días. $\mathrm{El} \mathrm{pH}$ se mantuvo por debajo de 4, variando de 3.49 a 3.39. Respecto al porcentaje de acidez, este se mantuvo por encima de $3 \%$, variando desde $3.65 \%$ a $3.56 \%$. La razón por la cual el pH y el porcentaje de ácido láctico se mantienen estables en el periodo evaluado, es debido a que las bacterias acidolácticas, al tener suficiente cantidad de carbono, producen acidez necesaria para eliminar a la mayor parte de microorganismos de la putrefacción presentes en los lodos residuales. Al tener poca competencia por los recursos las bacterias acidolácticas pueden desarrollarse de manera estable durante un tiempo considerable (García, 2008).

Evaluación de la fitotoxicidad del ALA de lodo residual en semillas de lechuga

En la Tabla 10, se muestra los resultados asociados al ensayo de toxicidad aguda con semillas de lechuga; se observa que respecto al Porcentaje de Germinación Relativo (PGR), tomando en cuenta como criterio de germinación la aparición visible de la radícula, las diluciones $0.1 \%$ y $1 \%$ tuvieron un alto porcentaje de germinación de $100 \%$ y $98.5 \%$ respectivamente. Los valores de $\mathrm{pH}$ de dichas diluciones $6.75(0.1 \%)$ y 4.94 (1\%) podrían haber influenciado directamente sobre la absorción de los nutrientes por parte de las semillas, ya que, entre los valores cercanos de $\mathrm{pH}$ 5.5-7.0, se encuentra la mayor disponibilidad de nutrientes; fuera de este rango las formas en que se pueden encontrar los nutrientes resultan inaccesibles para ser absorbidos, (Gilsanz, 2007). En este sentido, los valores de pH de las diluciones $0.1 \%$ y $1 \%$ sumado a los bajos valores de conductividad eléctrica de $0.7 \mathrm{dS} . \mathrm{cm}^{-1}$ y $1.2 \mathrm{dS} . \mathrm{cm}^{-1}$

Tabla 9. Concentración de metales pesados del abono orgánico de lodo residual de PTAR de industria cervecera.

\begin{tabular}{lccc}
\hline $\begin{array}{c}\text { Metales } \\
\text { pesados } \\
(\mathrm{ppm})\end{array}$ & $\begin{array}{c}\text { ALA de } \\
\text { lodo } \\
\text { residual }\end{array}$ & $\begin{array}{c}\text { Biosol de } \\
\text { lodo } \\
\text { residual }\end{array}$ & $\begin{array}{c}\text { Norma } \\
\text { EPA 503 }\end{array}$ \\
\hline $\mathrm{Pb}$ & 0.54 & 28.56 & 840 \\
$\mathrm{Cd}$ & N.D & 2.11 & 85 \\
$\mathrm{Cr}$ & 2.01 & N.D & 3000 \\
\hline
\end{tabular}






Figura 11. Índice de germinación en semillas de lechuga.

respectivamente, ofrecieron las mejores condiciones de germinación para las semillas de lechuga.

Según el análisis de varianza, existieron diferencias significativas $(\mathrm{p}<0.05)$, entre las diluciones dosisrepuesta al quinto día de terminado el ensayo de evaluación de porcentaje de germinación con una varianza de $10.24 \%$. Se realizó también una prueba de comparación de Tukey, y se encontraron tres grupos diferentes en el número de semillas germinadas (A, B y C). El control $(0 \%)$ y las diluciones $0.1 \%, 1 \%$ no presentaron diferencias significativas en el número de semillas germinadas, asimismo, los porcentajes de germinación de dichas diluciones fueron muy altos (98.5\% y $100 \%$ ), lo cual indica que no hay efectos fitotóxicos del ALA en el proceso de germinación de las semillas de lechuga a las concentraciones de $0.1 \%$ y $1 \%$. Sin embargo, debido a los bajos valores de $\mathrm{pH}$ y altos valores de conductividad eléctrica en los demás tratamientos, se observaron efectos fitotóxicos en la germinación de semillas (emergencia de cotiledones o cotiledones e hipocótilo solamente, pero sin emergencia de la radícula), que se expresó en valores de PGR de $81.17 \%$ (Dilución 5\%) y $0 \%$ (Diluciones $7.5 \%, 8.8 \%, 10 \%$ y $50 \%$ ). Siguiendo la metodología de Varnero et al. (2007), el IG permite evaluar el grado de madurez requerido para los residuos orgánicos que se seleccionen como componente base en la elaboración de sustratos especializados de uso agrícola. En la Figura 11 y Tabla 10, se aprecian los valores del Índice de Germinación (IG) en semillas de lechuga para las diferentes diluciones dosis-respuesta de ALA de lodo residual.

Zucconi et al., (1981), Emino \& Warman (2004) y Varnero et al. (2007) mencionan que los valores de PGR, CR e IG deben encontrarse por encima de $80 \%$ para considerar que la sustancia empleada no contiene elementos fitotóxicos, valores de IG entre 80 y $50 \%$ indican una presencia moderada, mientras que valores por debajo de $50 \%$ revelan una fuerte presencia de fitotoxinas. Para el caso del ALA de lodo residual, el efecto en el índice de germinación, más que por sustancias fitotóxicas, va a estar dado por los valores de $\mathrm{pH}$ y conductividad eléctrica que presenten las diluciones. Al respecto, Zapata et al., (2005) afirman que estos casos se deben a una alta concentración de sales; considerando que la tolerancia de la lechuga a la salinidad oscila entre 1.4 a $2.0 \mathrm{dS} . \mathrm{m}^{-1}$ (Faquin \& Furlani, 1999), parámetro que es considerado para el monitoreo de este cultivo en hidroponía. Otro factor implicado es la acidez, ya que el pH óptimo de la lechuga es de 5.8 (Andriolo et al., 2005). Por ello, se obtuvo como resultado que, a menor dilución de ALA, mayor resultaba el IG (ver Figura 11), y, para obtener el mayor IG (94.9\%), el ALA tuvo que diluirse al 0.1\% para neutralizar los efectos fitotóxicos de su elevada acidez y salinidad. Con la dilución al $0.1 \%$ la salinidad se redujo a $0.7 \mathrm{dS} . \mathrm{m}^{-1}$, valor que no indica problema para su uso en campo, según la clasificación de aguas de riego establecida por la FAO (Ayers \& Westcott, 1985). En la dilución 1\%, el IG fue de $74.6 \%$ que se encuentra dentro de los valores de IG entre 50\% y $80 \%$ (fitotoxicidad moderada). Con respecto a la dilución del 5\% del ALA con un IG de $8.5 \%$ (fuerte presencia de fitotoxicidad), se observaron plántulas pequeñas y débiles respecto al control, es decir hubo un efecto adverso sobre el crecimiento y el vigor de las plántulas de lechuga evidenciado por el crecimiento de radícula de menor longitud, emergencia de cotiledones sin emergencia de radícula, poco desarrollo de los pelos absorbentes e inhibición en la longitud de las radículas e hipocótilo, que según Sobrero \& Ronco (2004), son indicadores del crecimiento anormal de las plántulas. Por otro lado, no hubo diferencias significativas con respecto al número de semillas germinadas entre las diluciones $0.1 \%$ y $1 \%$, sin embargo, sus IG resultaron

Tabla 10. Parámetros asociados al ensayo de toxicidad aguda.

\begin{tabular}{cccccccc}
\hline Diluciones & pH & $\begin{array}{c}\text { C.E. } \\
(\mathrm{dS} / \mathrm{cm})\end{array}$ & $\begin{array}{c}\mathrm{N}^{\mathrm{O}} \text { Semillas } \\
\text { germinadas }\end{array}$ & $\begin{array}{c}\text { PGR } \\
(\%)\end{array}$ & $\begin{array}{c}\text { Elongación } \\
\text { de } \\
\text { la radícula } \\
(\mathrm{mm})\end{array}$ & $\begin{array}{c}\text { CRR } \\
(\%)\end{array}$ & $\begin{array}{c}\text { IG } \\
(\boldsymbol{\%})\end{array}$ \\
\hline Control (0\%) & 7.2 & 0.8 & $20^{\mathrm{A}}$ & - & 27.1 & - & - \\
$\mathbf{0 . 1 \%}$ & 6.75 & 0.7 & $20^{\mathrm{A}}$ & 100 & 25.7 & 94.9 & $\mathbf{9 4 . 9}$ \\
$\mathbf{1 \%}$ & 4.94 & 1.2 & $19.7^{\mathrm{A}}$ & 98.5 & 20.5 & 75.7 & $\mathbf{7 4 . 6}$ \\
$\mathbf{5 \%}$ & 3.99 & 3.5 & $16.3^{\mathrm{B}}$ & 81.17 & 2.8 & 10.4 & $\mathbf{8 . 5}$ \\
$\mathbf{7 . 5 \%}$ & 3.93 & 4.8 & $0^{\mathrm{C}}$ & 0 & 0 & 0 & $\mathbf{0}$ \\
$\mathbf{8 . 8 \%}$ & 3.9 & 5 & $0^{\mathrm{C}}$ & 0 & 0 & 0 & $\mathbf{0}$ \\
$\mathbf{1 0 \%}$ & 3.9 & 5.1 & $0^{\mathrm{C}}$ & 0 & 0 & 0 & $\mathbf{0}$ \\
$\mathbf{5 0 \%}$ & 3.7 & 15 & $0^{\mathrm{C}}$ & 0 & 0 & 0 & $\mathbf{0}$ \\
\hline
\end{tabular}


diferentes, esto debido a las diferencias en el tamaño y desarrollo de la radícula e hipocótilo, ya que si bien el $\mathrm{pH}$ de 4.94 (dilución 1\%) permitió tener un alto porcentaje de germinación, esto no significó que todas las plántulas tuvieran un óptimo desarrollo. Para las demás diluciones $(7.5 \%, 8.8 \%, 10 \%$ y $50 \%)$ el IG resultó ser $0 \%$ (fuerte presencia de fitotoxicidad), esto debido a valores de $\mathrm{pH}$ ácidos menores a 4 y una alta conductividad eléctrica que afectaron la germinación de las semillas de lechuga y el crecimiento en cuanto a la longitud y forma de las radículas. Analizando los resultados obtenidos, se observó que la dilución $0.1 \%$ es la que mejor favorece a las plántulas de lechuga, debido a que presentó mayor IG (94.9\%). Resultados similares, fueron reportados por Peralta (2010) usando biol de excreta de ganado vacuno con un IG de $84.54 \%$ a una dilución de $0.1 \%$ de biol; Coronado (2010) reportó un mayor IG con una dilución del 10\% para bioles de biodigestores de Lima y Huancayo; y Román (2012) reporto un IG de $99.49 \%$ a una dilución de $0.01 \%$ de biol de excretas de cuy.

\section{Conclusiones.}

1. El tratamiento de los lodos residuales de PTAR de una industria cervecera con la combinación de melaza y B-lac mediante la técnica de fermentación homoláctica, permite la estabilización y uso de los lodos residuales como abono orgánico líquido en un tiempo muy reducido.

2. El tratamiento T9, cuyas proporciones de lodo residual, melaza y B-lac, fueron de $75 \%, 20 \%$ y $5 \%$ respectivamente, resultó ser la mejor combinación que presentó un menor valor del $\mathrm{pH}$ al quinto día de fermentación y estabilidad por un periodo de 30 días.

3. Según los análisis microbiológicos $y$ parasitológicos del ALA y biosol de lodo residual, estos muestran ser productos inocuos, libres de microorganismos patógenos que puedan generar riesgos en la salud a las personas que puedan manipularlos, además tampoco representa riesgo de contaminación en los suelos de cultivos.

4. Se determinó que la dosis óptima de ALA de lodo residual fue de $0.1 \%$, la cual no generó efectos adversos en el poder germinativo ni en la germinación de semillas de lechuga (Lactuca sativa L.) variedad Hardy, y tampoco ocasionó efectos de toxicidad en el crecimiento normal de las plántulas de lechugas germinadas.

\section{Literatura citada.}

Aldón D. 2008. Estrategia Ambiental de aprovechamiento de la macroalga Ulva lactuca (lechuga de mar) a través del proceso de ensilaje. Tesis de Ingeniero Ambiental. Universidad Nacional Agraria La Molina. Lima-Perú.

Aloisi R. 1995. Decomposição de resíduos da indústria cítrica em solos de textura média. Piracicaba. 255p. Tese (Livre Docência). Escola. Superior de Agricultura "Luiz de Queiroz”, Universidade de São Paulo.
Andriolo J.L., Luz G.L., Witter M.H., Godoi R.S., Barros G.T. \& Bortolotto O.C. 2005. Growth and yield of lettuce plants under salinity. Horticultura Brasileira. 23 (4): 931934.

AOAC (Association Official Analytical Chemists). 1998. Codex-Adapted 942.15.

Ayers R.S. \& Westcott D.W. 1985. Water quality for agriculture. FAO. Irrigation and Drainage Paper 29. Rev.1, Rome, Italy. 174 p.

Beltrame K., Aloisi R., Vitti G. \&Boluda R. 1999. Compostaje de un lodo biológico de la industria cervecera con aireación forzada y virutas de eucalipto. pp 165-180.

Blum D. \& Feachem R. 1985. Health aspects of nigtsoil and sludge use in agriculture and agriculture. III. Report 5/85. Dvebendorf: International Reference Centre for Waste Disposal. London. UK.

Bossio P. 2007. Obtención de un biofertilizante basado en residuos de pescado y roca fosfatada. Tesis de Biólogo. Universidad Nacional Agraria La Molina. pp 150. Lima Perú.

Boucourt R., Carrasco E., López A., Rodríguez Z. \& Gutiérrez O. 2006. Microbiota aerobia en caña fermentada con excreta vacuna como alternativa alimentaria. Revista Cubana de Ciencia Agrícola, Tomo 40, No 3 pp. 279-281.

Braile P. \& Cavalcanti J. 1993. Manual de tratamiento de aguas residuales industriales. São Paulo: CETESB, pp764.

Brown S., Henry Ch., Chaney R., Compton H. \& De Volder P. 2003. Using municipal biosol ids in combinat ion with other residuals to restore metal- contaminated mining areas. Plant Soil. 249: 203-215.

Capman H. \& Pratt P. 1973. Métodos de análisis para suelos, plantas y aguas. Editorial Trillas. México. Uso de los laboratorios de LASPAF - Facultad de AgronomíaUNALM.

Carrasco S., Scarincini E. \&Simonetta C. 2002. Antibacterial Activity of Lactic Acid bacteria Isolated from Argentinian Dairy Products. The Australian Journal of Dairy Technology. Vol. 57. No. 1, 15-19.

Castrejón J., Barrios A., Jiménez B., Maya C., Rodríguez A. \&González A. 2000. Evaluación de la calidad de lodos residuales de México. Instituto de Ingeniería. Grupo de Tratamiento y Reúso. Universidad Nacional Autónoma de México.

Coronado C. 2010. Efecto de los factores físico-químicos sobre las poblaciones microbianas mesófilas nativas provenientes de biodigestores artesanales. Tesis Biólogo. Universidad Nacional Agraria la Molina. Lima - Perú.

Cuevas J., Seguel S., Ellies Sch. \& Dörner J. 2006. Efectos de las enmiendas orgánicas sobre las propiedades físicas del suelo con especial referencias a la adición de lodos urbanos R.C.Suelo Nutr. Veg. 6 (2) 2006 (1- 12) J. Soil Sc. Plant. Nutr.6 (2), pp. 78-89.

Di Marzio W. 2004. Microbiología de lodos activados: una herramienta retrospectiva y predictiva de la depuración de efluentes. Revista Agua Latinoamérica. Cap 12, pp 45-50.

Emino E \& Warman P. 2004. Biological assay for compost quality. Compost sdence \& utilization, vol 12, no. 4, 342348.

Faquin V. \& Furlani P.R. 1999. Cultivo de hortaliças de folhas em hidroponia em ambiente protegido. Informe Agropecuário (Brasil). 20 (200/201): 99-104. 
Felipó M. 1995. Reutilización de residuos urbanos y posible contaminación. En: Gestión y utilización de residuos urbanos para la agricultura. Madrid: Editorial Aedos, p. 23-36.

Garcés A., Berrio L., Ruiz S., Serna G. \& Builes A. 2004. Ensilaje como fuente de alimentación para el ganado. Revista Lasallista de Investigación, Vol. 1. Antioquia, Colombia. pp. 66-71.

García, L. 2008. Uso de bacterias probióticas en el ensilado de residuos de pescado. Tesis de Biólogo. Universidad Nacional Agraria La Molina. Lima - Perú.

Gilsanz J. 2007. INIA-Programa Nacional de Producción Hortícola Est. Expt. Las Brujas. Instituto Nacional de Investigación Agropecuaria. Uruguay.

Guccione L. 2009. Tratamiento de los residuos orgánicos del comedor universitario de la UNALM para su uso como alimento para cerdos en crecimiento. Tesis Ingeniero Ambiental. Universidad Nacional Agraria la Molina. pp 180. Lima - Perú.

ICMSF (International Commission on Microbiological for Food). 1983. Segunda Edición. Vol. 1 Part II. Editorial Acribia.

Kimura R. 2005. Evaluación de los efectos del producto "ENZYMPLUS" (activador biológico) en la elaboración de compost utilizando dos tipos de estiércol (vacuno y ovino). Tesis de Magister Scientiae de Ciencias Ambientales. Universidad Nacional Agraria La Molina. Lima- Perú.

Lindgren, E \& Dobrogoz, J. 1990. Antagonic activities of Lactic Acid Bacteria in Food and Feed Fermentation. FEMS. Microbial. Rev. 87, 149-164.

Madigan M., Martinko J. \& Parker J. 2004. Brock Biología de los Microorganismos. 10 ed. Madrid, Prentice Hall. $1096 \mathrm{p}$.

Marambio C. \& Ortega R. 2003. Uso potencial de lodos derivados del tratamiento de aguas servidas en la producción de cultivos en Chile. Revista Agronomía y Forestal UC 20, pp. 20-23.

Miller, W \& Donahue, L. 1995. Soils in our environment. 7th ed. Prentice Hall. Englewood Cliffs, NJ. p 105.

Morales M. 2005. Digestión Anaerobia de Lodos de Plantas de Tratamiento de Aguas y su aprovechamiento. Tesis de Licenciatura para optar el título profesional de Ingeniería Química con área en Ingeniería Ambiental. Universidad de las Américas Puebla. Puebla- México, pp 95-115.

Muck R \& Kung L. 1997. Effects of silage additives on ensiling proceedings from the silage: field to feed bunk. North American Conference Hershey, Pennsylvania, USA February 11-13 pp. 187-199.

Oropeza N. 2006 Lodos residuales: estabilización y manejo Caos Conciencia 1: 51- 58. México.

Peña N. 2008. Utilización de residuos de pota (Dosidicus gigas) para la elaboración de un fertilizante orgánico. Tesis de Ingeniero Ambiental. Universidad Nacional Agraria La Molina. 155p. Lima - Perú.

Peralta L. 2010. Determinación de parámetros óptimos en la producción de Fast biol usando las excretas del ganado lechero del establo de la UNALM. Trabajo de
Investigación Biólogo. Universidad Nacional Agraria la Molina. 150 p. Lima - Perú.

Pereira-Neto J., Stentiford E., Mara D. \&Smith D. 1987. Survival of faecal indicator micro-organisms in refuse sludge compost using the aerated static system. Waste Management and Research. 4:397-406.

Rodríguez C. 2004. Residuos Ganaderos. Cursos de Introducción a la Producción Animal. Facultad de Agronomía y Veterinaria (FAV). Universidad Nacional de Río Cuarto (UNRC). Córdoba, Argentina. pp.1-7.

Román C. 2012. Tratamiento biológico de la cuyinaza de la granja de cuyes de Cieneguilla de la UNALM a través de un proceso de fermentación homoláctica. Tesis Ingeniero Ambiental. Universidad Nacional Agraria la Molina. pp 150. Lima - Perú

Scora W. \& Chang C. 1997. Essential oil quality and heavy metal concentrations of peppermint grown on a municipal sludge-amended soil. J. Environ. Qual. 26: 975-979.

Siura, S. \& Dávila, S. 2008. Effect of green manure rotation, biol and cultivar on the production organic spinach (Spinacea oleracea). 16th IFOAM. Organic World Congress. Modena, Italy. pp 4.

Sobrero M.C. \& Ronco A. 2004. Ensayo de toxicidad aguda con semillas de lechuga (Lactuca sativa L.). pp. 71-79. En: G. Castillo (ed.) Ensayos Toxicológicos y Métodos de Evaluación de Calidad de Aguas. Ottawa-Canadá.

Sotil F. 2007. Dinámica poblacional de los microorganismos del grupo de coliforme, en el proceso de Biodegradación aeróbica y anaeróbica de los abonos líquidos orgánicos Biol y Purin. Tesis de Ingeniero Ambiental. Universidad Nacional Agraria La Molina. Lima - Perú.

Suarez M. 2009. Caracterización de un compuesto orgánico producido en forma artesanal por pequeños agricultores en el departamento del magdalena. Universidad Nacional de Colombia sede Palmira.

Tobía C. \& Vargas E. 2000. Inóculos bacterianos: una alternativa para mejorar el proceso fermentativo en los ensilajes tropicales. Nutrición Animal Tropical, Vol. 6, $\mathrm{N}^{\mathrm{o}}$ 1. Costa Rica. pp. 129-143.

Varnero M., Rojas C.\& Orellana R. 2007. Índices de fitotoxicidad en residuos orgánicos durante el compostaje. Revista de ciencia del Suelo y Nutrición Vegetal. 7 (1) (28-37).

WHO (World Health Organization). 2004. Integrated guide to Sanitary Parasitology Regional Office for eastern Mediterranean. Regional centre for environmental health activities. 120.

Yabroudi C., Almarza J., Pedrique F., Cárdenas C. \& Herrera L. 2009. Optimización del proceso de tratamiento de aguas residuales de una industria cervecera. Interciencia vol. $34 \mathrm{n}^{\circ} 11 \mathrm{pp}$ 764-770.

Zapata N., Guerrero F. \& Polo A. 2005. Evaluación de corteza de pino y residuos urbanos como componentes de sustrato de cultivo. Agricultura Técnica (Chile). 65 (4): 378-387.

Zucconi F., Pera A., Forte M. \& De Sertoli M. 1981. Evaluating toxicity in immature compost en: biocycle (22): 54-57.

\footnotetext{
${ }^{1}$ Av. Del Parque Sur 129, Oficina 301 - Corpac, San Isidro. Lima 12, Perú. beatrizcf20@ gmail.com.

${ }^{2}$ Laboratorio de Biorremediación. Facultad de Ciencias, Universidad Nacional Agraria La Molina. Av. La Molina s/n, Lima 12, Perú. jjm@lamolina.edu.pe.
} 